\title{
Reshaping the Lower Face Using Injectable Fillers
}

\author{
André Braz Camila Cazerta de Paula Eduardo² \\ ${ }^{1}$ Dermatologia Laser Cosmiatria Clinic, Rio de Janeiro, RJ, Brazil \\ 2Dermatologist, Aesthetike Plastic Surgery and Dermatology, \\ Sao Paulo, SP, Brazil
}

\begin{abstract}
Address for correspondence André Braz, MD, Dermatologia Laser Cosmiatria Clinic, R Visconde de Pirajá 330, Rio de Janeiro, RJ 22640-000, Brazil (e-mail: avbraz@globo.com).
\end{abstract}

Indian J Plast Surg:2020;53:207-218

\begin{abstract}
Keywords

- cosmetic therapies

- dermal filler

- facial rejuvenation

- hyaluronic acid and calcium hydroxylapatite

- lower face

- nonsurgical

The lower third is very important for the pleasant appearance of the face. A well-contoured jawline is desirable in men and women, giving a perception of beauty and youth. It is also key to sexual dimorphism, defining masculine and feminine characteristics. The nonsurgical rejuvenation and beautification of the lower third of the face is becoming more frequent. Injectable fillers can reshape the jawline, lift soft tissues, and improve facial proportions, effectively improving the appearance of the area.

It is paramount to understand the facial anatomy and perform a good facial assessment in order to propose a proper aesthetic treatment plan. The aesthetic goal of the rejuvenation approach is to redefine the mandibular angle and line. In young patients, beautification can be achieved through correction of constitutional deficit or enhancement of the contour of the face, improving the facial shape. It is very important to possess knowledge of facial anatomy and of the aging process in order to deliver effective and safe results.

In this article, we discuss the anatomy of the lower third of the face, facial assessment, aging process, and treatments of the chin, prejowls and mandibular line and angle with injectable fillers. The authors' experience in the approach of this area is discussed.
\end{abstract}

\section{Introduction}

A beautiful face cannot be defined by a mathematical formula. ${ }^{\text {I }}$ It reflects the bone structure, position and volume of the subcutaneous tissue, skin quality, and the personality of each person. The harmonious proportions of the facial thirds and other features such as eyes, nose, lips, chin and neck are paramount for an attractive face..$^{1-4}$

The lower third is very important for the pleasant appearance of the face. ${ }^{5-7} \mathrm{~A}$ well-contoured jawline, a defined line from the mandible angle to the chin, is desirable in men and women, ${ }^{6}$ giving us a perception of beauty and youth. It is also key to sexual dimorphism, and defining masculine and feminine characteristics. ${ }^{5}$ Men have a squarer face than women, with a sharp jawline and a more pronounced jaw angle. ${ }^{7-9}$ Women may have a defined mandibular angle, but the mandibular pillar is more delicate, providing a more oval facial shape. ${ }^{9}$ The chin is of great importance in men's attractiveness. ${ }^{8}$ It is larger and stronger in men, whereas in women it is rounder and subtle ${ }^{10}$ ( - Fig. 1).

The facial aging process is multifactorial, resulting from changes in all layers, the soft tissue and underlying skeleton, ${ }^{10,11}$ which occurs at a different pace among individuals. There is skin atrophy, subcutaneous fat redistribution, and bone remodeling and resorption.

In the lower face, the mandible undergoes an anterior and inferior resorption, which can be aggravated by the loss of teeth. The angle of the mandible increases with age, as a result of resorption in its inferior border. The chin becomes more anterior and shorter with aging. ${ }^{10}$
License terms

()(1) $\Theta \circledast$ 


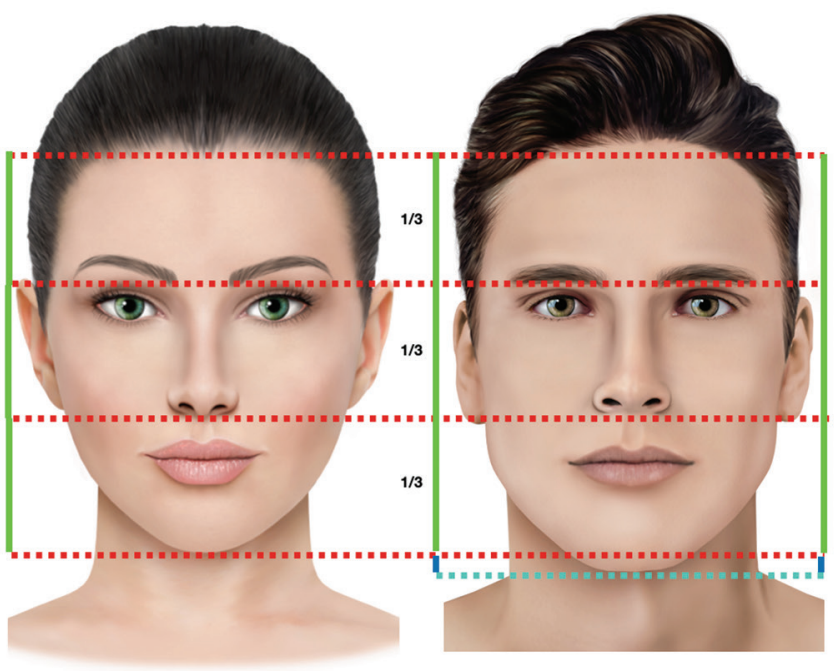

a

b



C

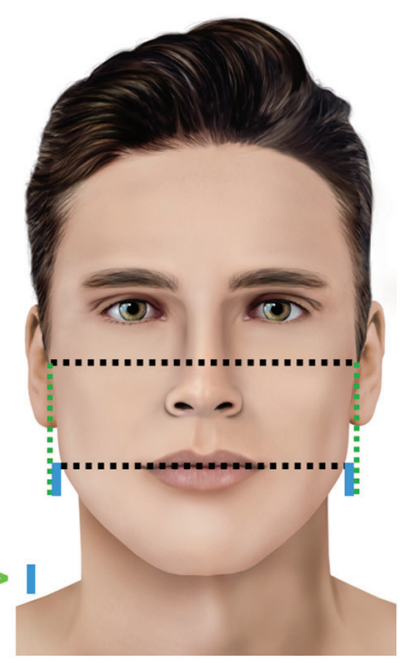

d

Fig. 1 Facial dimorphism. One of the aspects of beauty is the proportions among the three thirds of the face. In women, the height of the three thirds is similar (a), whereas in men, there is predominance of the lower third of the face $(\mathbf{b})$. In women, there is a predominance in the middle third of the face: bizygomatic distance is wider than the bigonial distance (c). In men, theses distances are almost 1:1.

There is atrophy of superior and inferior mandibular fat compartment and dehiscence of the mandibular septum, causing the fat pads to move downward to the neck.

These changes, together with skin atrophy, result in loss of the jawline definition and formation of the jowls.,5,12 The depressor labii inferioris, depressor anguli oris and platysma muscles contribute to the worsening of the jawline contour, as they pull the soft tissue downwards. ${ }^{5}$

A constitutional small or recessed chin may contribute to early loss of the jawline definition.

The nonsurgical rejuvenation and beautification of the lower third of the face are becoming more frequent, as they can effectively restore and improve the appearance of the area. ${ }^{6,713}$ Different methods can be used to address the different clinical aspects, such as microfocused ultrasound, ablative and nonablative lasers, radiofrequency, botulinum toxin and injectable fillers. Injectable fillers can reshape the jawline, lift soft tissues, and improve facial contours and proportions. $5,6,14$

To deliver aesthetic effective and safe results, it is critical to perform a good facial assessment and possess knowledge of facial anatomy to propose the priorities of treatment, using the proper techniques, in order to achieve the optimal outcomes.

In this paper, the essential anatomy will be discussed, and our experience of contouring and reshaping the jawline and chin with injectable fillers will be presented.

\section{Facial Assessment}

A global facial evaluation must be performed, analyzing the shape, balance and symmetry. It is important that any midface volume correction or restoration should be done prior to the lower face treatment, as this helps in repositioning and pulling the soft tissue upward. On the other hand, many patients are not able to understand their lower face deficiencies. Therefore, when treating the midface of a patient, the lower third should also be evaluated to optimize the facial proportions. ${ }^{2.7}$

The patient must be assessed at rest and animation in upright position. Photographs should be taken in the frontal, lateral and oblique positions. ${ }^{5.7}$ The careful examination includes palpation and evaluation of the teeth to identify any orthognathic and odontological problems that might interfere with the results and should therefore be addressed.

Attention should be given to the chin projection, length and width, labiomental sulcus, mandible angle, prejowl sulcus, jowls and cervicomental angle. . $5-7^{-7}$

When planning the aesthetic treatment, it is crucial to understand the patient's complaints and set realistic expectations.

The ideal indications are the presence of light-to-moderate loss of facial contour, light-to-moderate loss of volume, including patients with constitutional deficiencies in this region. The treatment can also be indicated for male patients, to enhance masculine characteristics, as the well-defined chin or jawline, in addition to female patients with oval or heart-shaped face, to strengthen the lower third, improving the facial contour. ${ }^{15}$

In severe cases of laxity, loss of contour and volume deficiencies, the surgical approach must be considered ${ }^{2,7}$ ( $\mathbf{- F i g .} \mathbf{1}$ ). In the case the patient is not eligible or refuses surgery, the limitations of the modality should be discussed, along with the combination of other methods of treatment such as laser devices, microfocused ultrasound and radiofrequency, to optimize the results. ${ }^{5}$

Prior to the injection, it is paramount to assess the patient's clinical history, allergies, prior injectable treatments, and use of medication. In the case of any dental problems or procedures in the previous 15 days, the injection should be postponed. 


\section{Anatomy}

\section{Bone}

The main structural component is the mandible, composed of an inferior portion that has a horseshoe appearance, and two perpendicular parts, the mandibular ramus.

Mandibular line is the mandibular area from the mentum to the angle of the mandible. ${ }^{16}$

\section{Soft Tissues}

The skin is thinner in the posterior areas of the face and becomes thicker anteriorly until the chin. ${ }^{6,7}$

There are four fat compartments in the mandibular region: the superior and inferior mandibular fat pads, which are located at the inferior border of the bone; a submandibular fat compartment; and the one that covers the parotid-masseteric fascia. ${ }^{16}$

In the lower third of the face, there is a different arrangement of layers anterior and posterior to the labiomandibular sulcus. ${ }^{5}$

Posterior to the sulcus, from superficial to deep: skin, superficial subcutaneous fat, platysma, deep fat, parotideomasseteric fascia, masseter muscle, and periosteum of the mandible (-Fig. 2 ).

Anterior to the labiomandibular sulcus, from superficial to deep: skin, subcutaneous fat, muscles of facial expression (depressor anguli oris, platysma, depressor labia inferioris, and mentalis), deep labiomandibular fat and deep mental fat in the chin, and periosteum $(- \text { Fig. } 3)^{5}$.

The mandibular ligament is located in the inferior margin of the labiomandibular sulcus, anterior to the jowls. The jowl deformity occurs due to the loose adherence of the platysma to the mandible, which is seen posterior to the labiomandibular sulcus. ${ }^{17}$

There is a different arrangement of the subcutaneous, which contributes to the formation of the labiomandibular sulcus in the aging process. Lateral to the sulcus, there is loose adhesion of skin to the underlying musculoaponeurotic layer, whereas medial to the sulcus, the adhesion is tight ${ }^{17}$ (-Fig. 4).

\section{Vasculature and Nerves}

It is crucial to know the location and depth of the facial artery, vein and facial nerve when performing fillers injections in the lower face.

The facial artery, a branch of the external carotid artery, crosses the inferior border of the mandible, anterior to the insertion of the masseter, ${ }^{5,6,16}$ together with the facial vein (Fig. 5). It is paramount to know its course to avoid vascular complications. They are located in deep fat, deep to the platysma. The facial artery is the main vessel that supplies blood to the face. It runs deep in the buccal fat, branching into the superior and inferior labial arteries close to the modiolus. As it ascends, in the nasolabial sulcus region, the facial artery becomes more superficial, continuing as angular artery. .,6,16 $^{5,16}$

Laterally and deeper to the facial artery, we can notice the facial vein. (-Figs. 5-7).

No major neurovascular structures were found in the subdermal plane overlying the platysma in the jawline.

The primary blood supply to the chin are provided by the mental arteries, which exit the mental foramen on the lateral chin, in line with the vertical axis of the second inferior premolar teeth, and midway between the lower and upper mandibular borders ( - Fig. 7). The mental arteries are terminal branches of the inferior alveolar arteries, which are branches of the maxillary artery.

The inferior labial artery and labiomental artery provide further blood supply to the region.

The submental artery is a cervical branch of the facial artery. It anteriorly runs from the exit of the submandibular gland over the mylohyoid and crosses over the mandible near the mandibular symphysis ${ }^{7}$ (-Figs. 6 and 7).



Fig. 2 Cadaveric dissection (a). The skin is folded back, showing the superficial fat compartments (b). Superficial fat and superficial musculoaponeurotic system (SMAS) are folded back (c). The superficial temporal artery, the parotid gland, the masseter muscle deeply, and the platysma muscle insertion in the mandible (d). The superficial temporal artery (red arrow), parotid gland (gray) masseter muscle (yellow arrow), platysma (light gray) facial vein (blue arrow), facial artery (white arrow), ascending to the face in the anterior masseter border, and buccal fat pad (green arrow). 


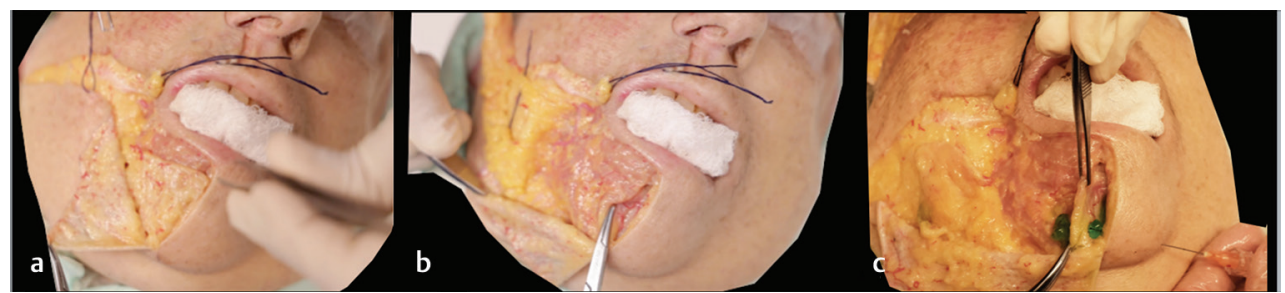

Fig. 3 The layers from superficial to deep: (a) Superficial subcutaneous fat (b) Deep mental fat and periosteum are exposed when the muscles are put laterally. (c) There are two possible depths of injection in the chin: blue colored gel injected in the superficial fat compartment and the green colored gel in the submuscular/supraperioteal plane.

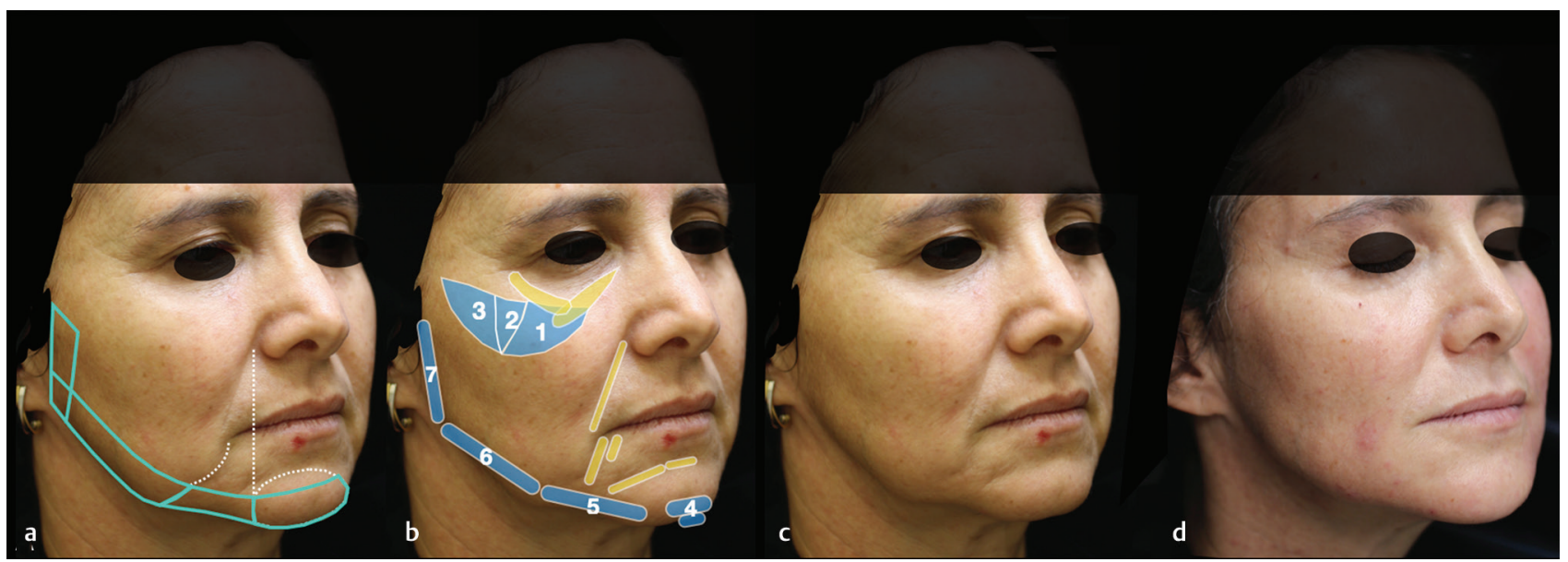

Fig. 4 The AB face technique approach to improve the structure of the face. It is important to restore the midface volume before approaching the lower face. Oblique view right side. (a) The marking of the areas to be injected. In yellow, the areas treated with hyaluronic acid (HA) filler Hydryalix gentle for refinement. The chin width is equivalent to the nose base width. (b) The filler was injected in the malar and zygomatic areas, from medial to lateral. The mental, prejowl, mandibular line, angle and ramus were treated. (c) Before and (d) after the treatment with Harmonyca and HA filler Hydryalix gentle (in yellow) with improved contours and proportion. The mandibular line was enhanced, softening the jowls, and keeping a feminine soft contour.

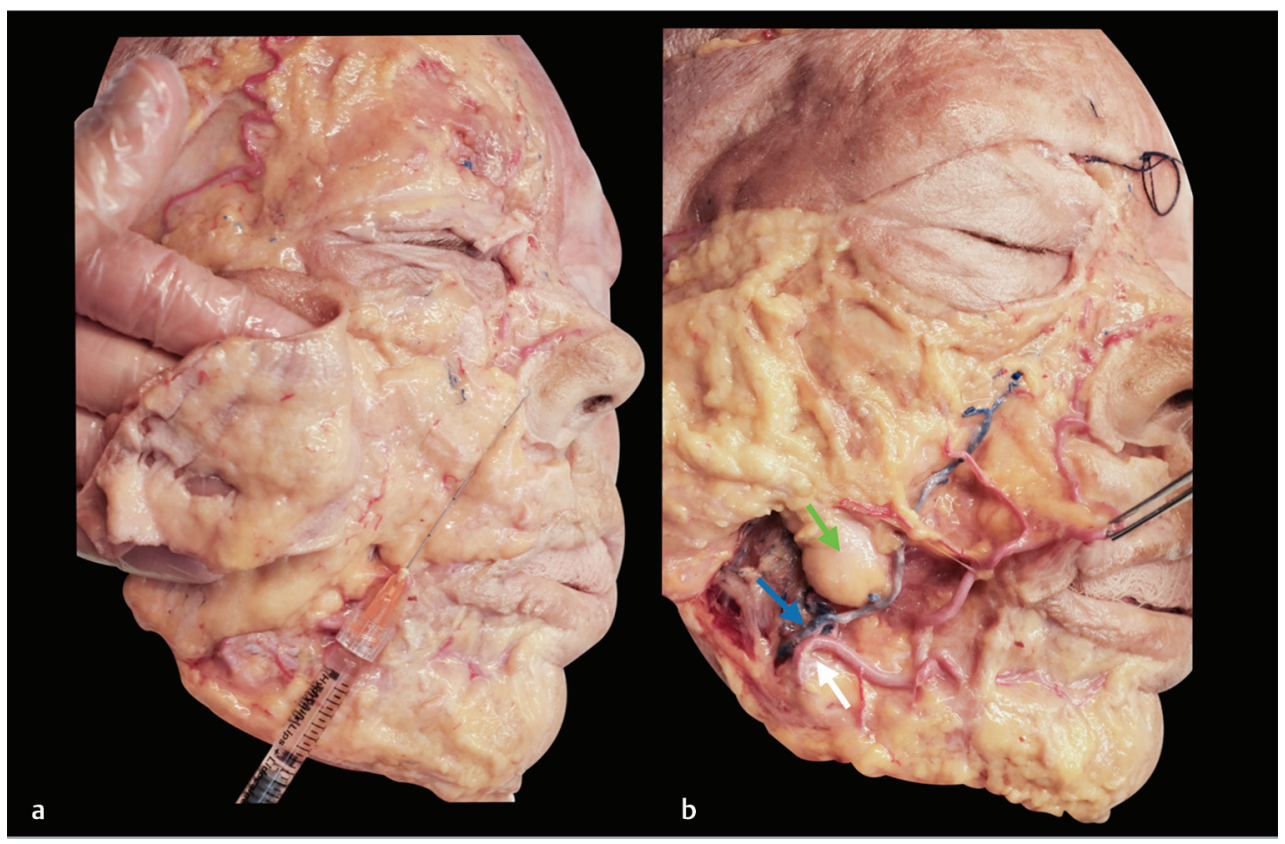

Fig. 5 Cadaveric dissections. (a) The skin is folded back, showing the superficial fat compartment of the midface. (b) The superficial fat compartments were folded back, showing the facial vein (blue arrow) and facial artery (white arrow) that cross the mandible anterior to the masseter and are located in the deep fat compartments. Buccal fat pad (green arrow). The facial artery runs in the superficial subcutaneous in the peri alar region. 


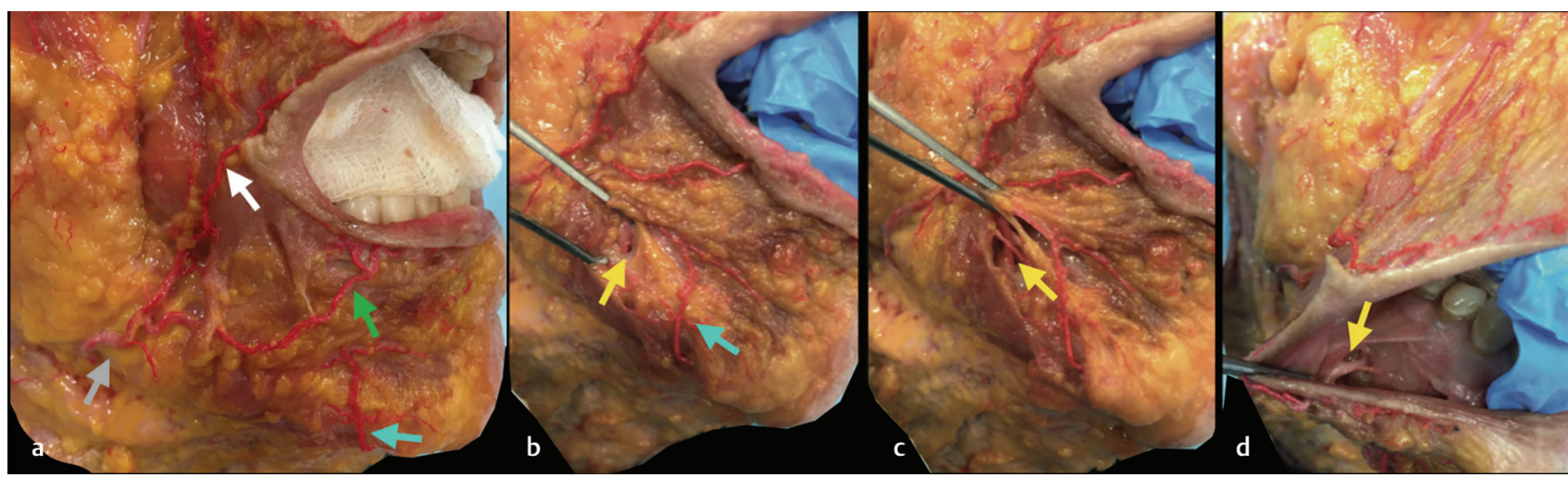

Fig. 6 Cadaveric dissections. (a) Facial artery (gray arrow); inferior labial artery (green); superior labial artery (white); submental artery (blue). (b) The depressor anguli oris (DAO) muscle is put aside to show the mental artery emerging from the mental foramen (yellow arrow). The submental artery (blue arrow). (c) The mental artery (yellow arrow), deep to the DAO. (d) An intraoral view of the mental nerve (yellow arrow) that emerges from the mental foramen is located in line with the vertical axis of the second premolar tooth.

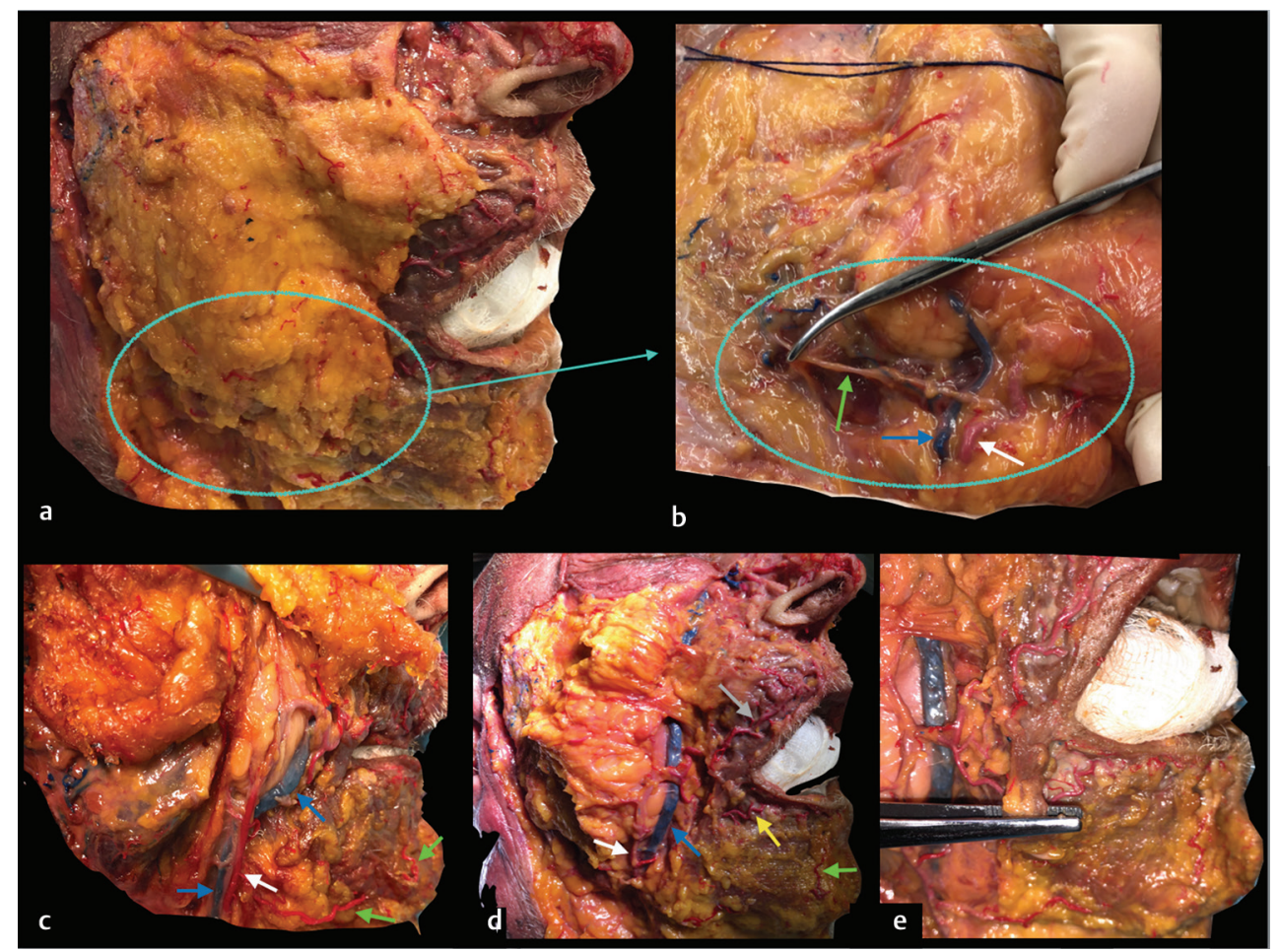

Fig. 7 (a) Superficial fat compartment. (b) The superficial fat compartment was folded back exposing the mandibular marginal branch of the facial nerve (green arrow) and the facial artery (white arrow) and vein (blue arrow). These structures are inferior to the mandibular border in this specimen, which is not the usual location for the mandibular marginal nerve anteriorly to the masseter, as discussed above. (c) Facial artery (white) and facial vein (blue) emerging in the face in anteriorly to the masseter border. The submental artery, cervical branch of the facial artery (green arrow) in the neck region, and in the chin. (d) Facial artery (white arrow) and facial vein (blue arrow). The inferior labial artery (yellow) and the superior labial artery (gray arrow), branches of the facial artery. The submental artery (green). (e) The depressor anguli oris (DAO) is clipped, showing the inferior labial artery deep to this muscle.

The mental nerve, branch of the trigeminal nerve, exits the mental foramen and provides sensory innervation. This is the reason the injection in the chin and prejowl area is painful (-Fig. 6). ${ }^{16}$

The motor innervation is given by the branches of the facial nerve, namely, the buccal and marginal mandibular nerves. Anterior to the masseter, the branches of the marginal mandibular nerve can be located above the mandibular border, whereas they are found 1 to $2 \mathrm{~cm}$ below the inferior mandibular border posterior to the anterior masseter border ( - Fig. 7)..$^{5,18}$

\section{The Parotid Gland}

The parotid gland is located in the preauricular area superiorly to the posterior region of the masseter muscle. 
The parotid duct arises in the anterior part of the gland and runs between the masseter and the parotideo-masseteric fascia, usually located in an imaginary line from the earlobe to the oral commissure ( - Fig. 2$)^{5}$

\section{The Treatment}

The lower third treatment with fillers can provide a reshape of the jawline, improving the facial contour, with a lifting effect of the cheek and neck (- Figs. 4, 8)..$^{5-7}$

Injectable fillers allow tridimensional augmentation of the chin, in horizontal, vertical and transverse dimensions (-Figs. 9 and $\mathbf{1 0}$ ).

To improve the structure, higher elasticity products are desirable. A softer gel may be used when the skin is too thin and for refinement treatments; in more dynamic areas, such as the perioral region, the corners of the mouth.

The $\mathrm{AB}$ face technique, a methodology described by the authors, was used in some patients described in this article. $A B$ stands for anatomy of beauty. The first step of this methodology, the AB structure, is based on the strengths and weaknesses of the different facial shapes and is intended to improve the contours and proportions of the face, thereby enhancing the patient's beauty. The second step is called $A B$ refinement, with the aesthetic goal of blending and smoothing the areas treated and correcting the remaining sulcus and grooves.

At the time of publication, the authors' products of choice for reshaping the lower face are high-elasticity, hyaluronic acid-based fillers.

We will present clinical cases where a composite matrix gel of $70 \%$ hyaluronic acid and 30\% calcium hydroxylapatite has been used. This premixed combination of materials has a high $G$ prime, which means a good resistance to deformation, besides having the biostimulatory effect of calcium hydroxylapatite (HArmonyCa, U.SK Under Skin, Brazil).
For the procedure, it is fundamental to carefully cleanse the whole area of treatment with an antiseptic solution, extending to the adjacent areas.

We prefer to use 22G blunt-tipped microcannulas to treat this area, which is 40 to $50 \mathrm{~mm}$ in length. With this method, a large area can be achieved with a single entry point, less bruising, and lesser chance of vascular injuries and complications.

The treatment of the different areas that compose the jawline will be briefly discussed in the present article. The jawline is an aesthetic unit, and the areas that should be treated must be selected according to each patient's needs and priorities.

\section{The Treatment of the Chin}

The width of the chin is equivalent to the medial intercanthal distance in women, whereas in men, the anatomical reference is the mouth width. Regarding the ideal projection, in male treatments, the chin should project approximately as far as the lower lip. In woman, the lower lip should be 1 to $2 \mathrm{~mm}$ beyond the chin (-Fig. 1$)^{6}$

To improve chin projection, the filler should mainly be placed in the anterior portion, the pogonion. To augment its length, the fillers should be inferiorly placed in the menton area.

In our experience, we mark a semicircle in the chin area, respecting the ideal width for men or women. In the symphysis area, between both mentalis muscles, consider an imaginary vertical line to help as a reference for symmetry evaluation. Thereafter, a horizontal line in the inferior border of the bone is marked. Finally, a parallel line is marked $1.5 \mathrm{~cm}$ proximally to this first horizontal line, resulting in a rectangular area to be filled ( - Figs. $4,8,10$ ).

The cannula entry point is lateral to the area of treatment, in the prejowl region, approximately $5 \mathrm{~mm}$ above the mandibular line. We recommend pinching this area, which makes the injection in the deep plane (deep to the mentalis muscle) easier.

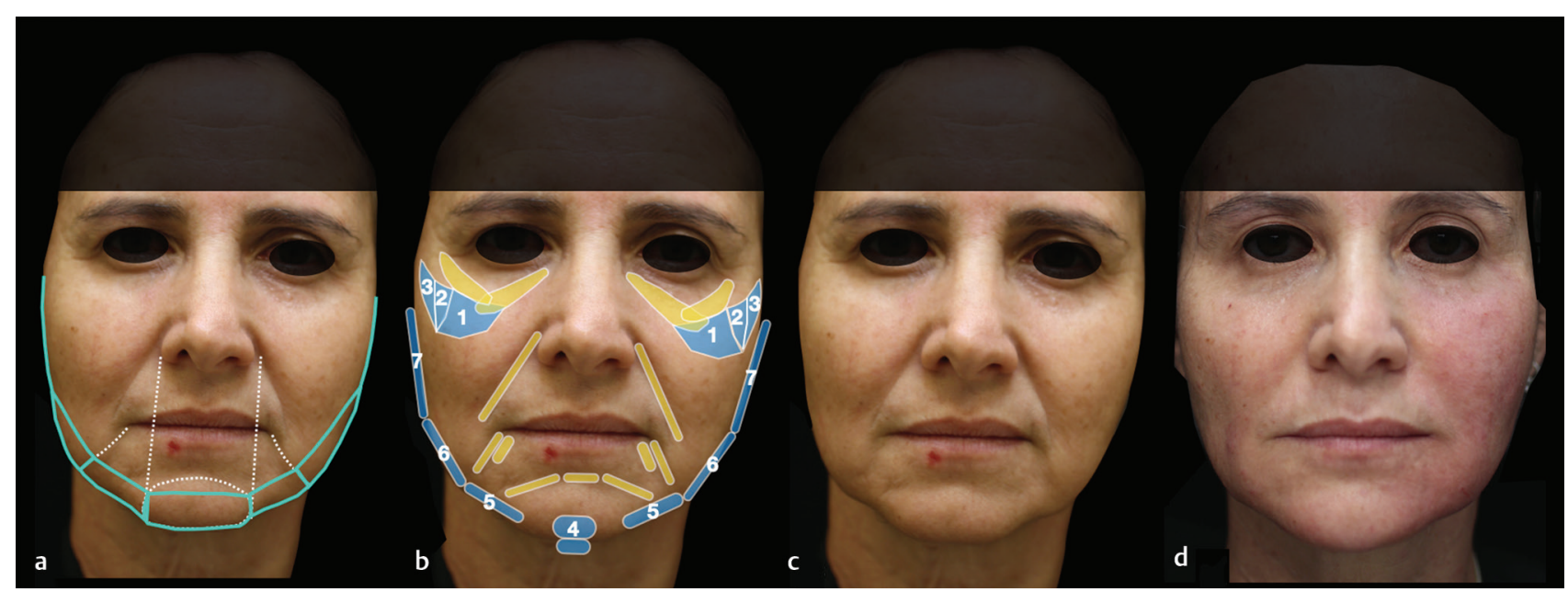

Fig. 8 The $A B$ face technique approach to improve the structure of the face. It is important to restore the midface volume before approaching the lower face, to achieve better results. Frontal view. (a) Show the authors' marking of the areas to be injected. The chin width is equivalent to the nose base width. (b) The filler was injected in the malar and zygomatic areas, from medial to lateral. In the lower third, the mental, prejowl, mandibular line, angle and ramus were treated. (c) Before and (d) after the treatment with Harmonyca, with improved contours and proportion. 


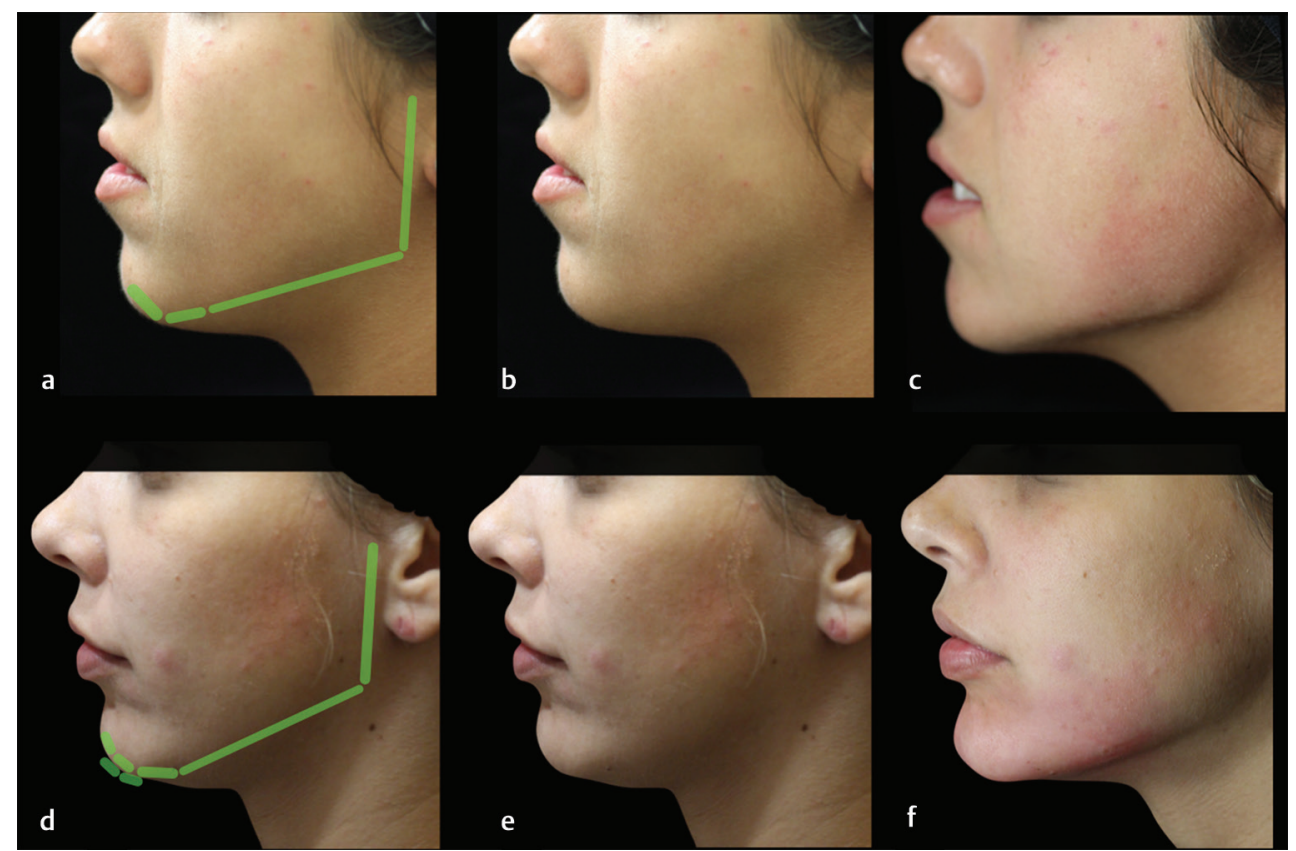

Fig. 9 Approach to enhance the mandibular contour in a young woman. (a) The areas for treatment: chin, prejowl, mandibular line, angle and ramus. (b) Before the treatment and (c) after, showing an improvement in the mandibular contour, and enhancing the face and neck transition. (d). The second patient areas for treatment. As she has a recessed chin, the mental area was treated anteriorly and inferiorly, to project and elongate. (e) Before the treatment and (f) after the treatment with filler, an enhanced mandibular contour and projection of the chin.

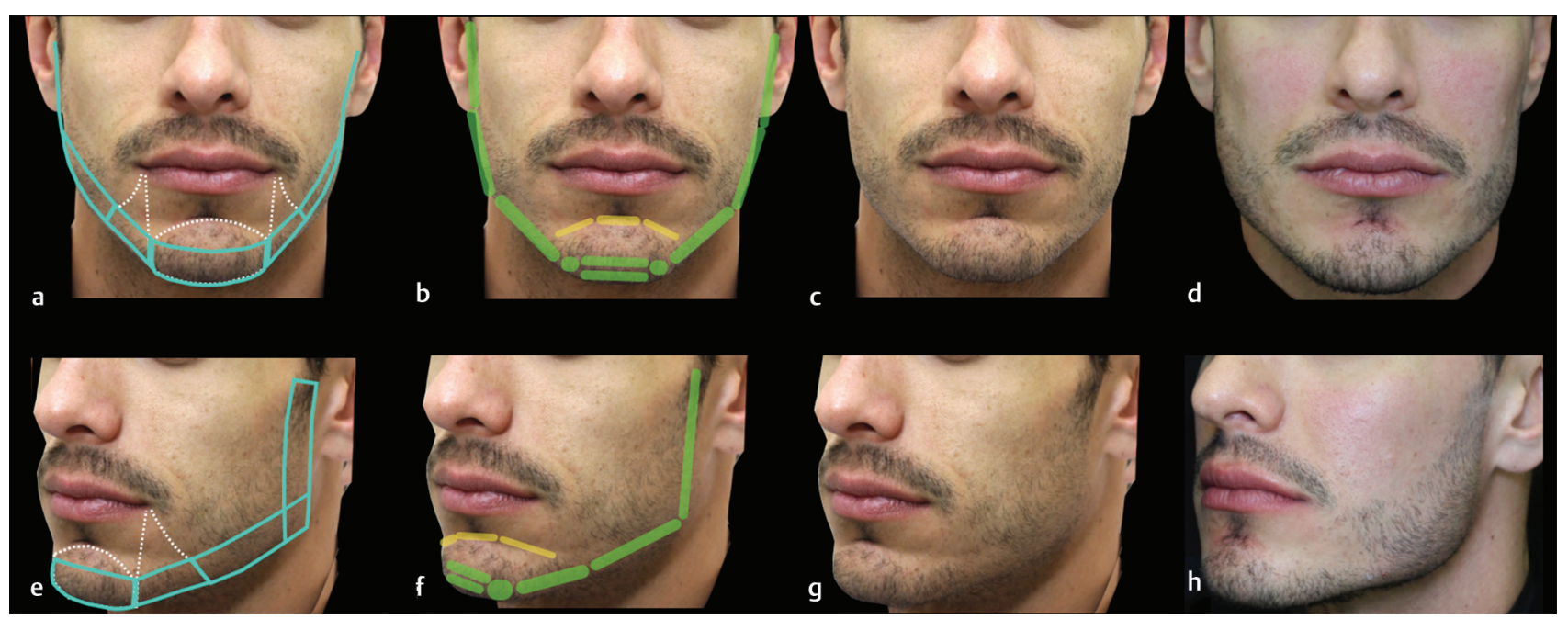

Fig. 10 (a) and (e) show the treatment marking for the injection. Of note, the chin width is similar to the mouth width. (b) and (f) show the areas treated, the chin, prejowl, mandibular line, angle and ramus. (c) and $(\mathbf{g})$ frontal and oblique views before the treatment. (d) and (h) frontal and oblique views, with an improved shape of the lower third. The bigonial distance is wider with a more defined jawline.

In general, we use 0.2 to $0.5 \mathrm{~mL}$ in each side, in the rectangular area, depending on the patient's needs and objective of the treatment.

To smoothen the area, additional injection can be performed in a more superficial plane, in the subcutaneous, using the same entry point (-Figs. $\mathbf{3}, \mathbf{1 1}$ ). In these cases, approximately $0.1 \mathrm{~mL}$ is retroinjected in each side. After the cannula withdrawal, we shape the area with precise and firm finger movements.

\section{The Treatment of the Prejowl Region}

It is very important to fill the depressed area, medial to the jowl, in order to restore the jawline. It is also important to avoid overfilling, especially in women, which could give the impression of a wider chin. To do so, we mark a rectangular area, using the medial limit, labiomandibular sulcus, or medial border of the jowl. The inferior limit is the mandibular border, and the superior limit is an extension of the horizontal superior line drawn for 


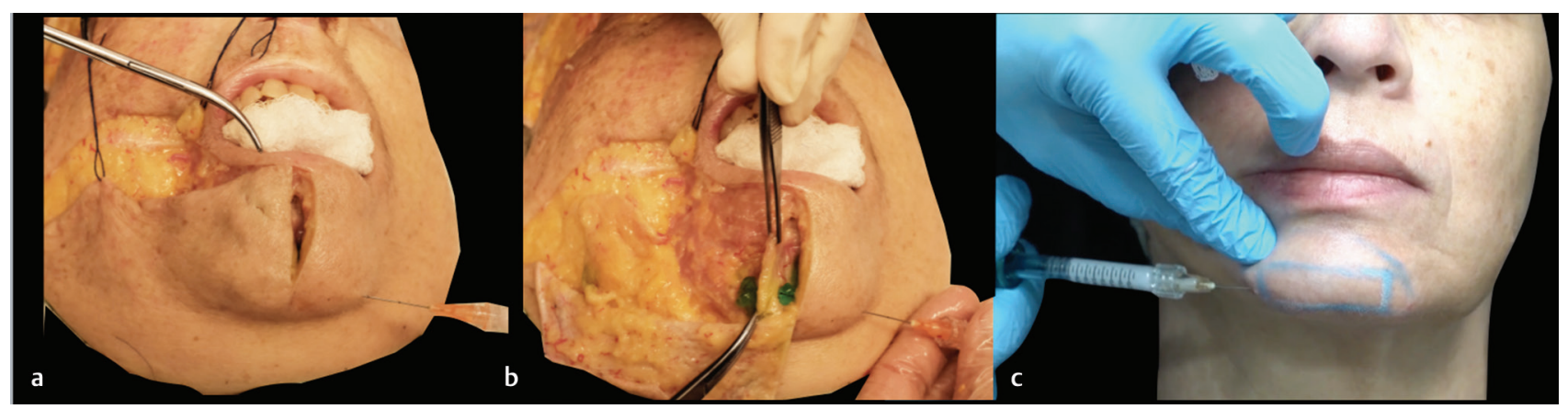

Fig. 11 Clinical-anatomical correlation. (a) Skin. (b) The authors usually inject the filler in both planes, deep to the muscle and in the superficial subcutaneous. (c) The lateral approach to the chin, using cannula, which the authors find safer than using a needle, because of the lower risk of vascular adverse events.

the chin treatment $(1.5 \mathrm{~cm}$ above the mandibular border) (-Figs. 4, 8, 10, 11)

The cannula entry point is lateral to the prejowl, mid-distance between the two horizontal lines. The technique is retroinjection in both submuscular and superficial subcutaneous planes (-Figs. 12-14).

\section{The Treatment of the Mandibular Line}

The area of the jowls, where there is ptosis and excess volume, should not be treated.

The area of treatment is posterior to the jowl until the mandibular angle and should be marked with two horizontal parallel lines. One in the mandibular inferior border and the other 1.5 to $2 \mathrm{~cm}$ above ( - Figs. $4, \mathbf{5}, \mathbf{8}, \mathbf{1 0}$ ).

The cannula entry point can be the same one used to fill the prejowl area in the jowl region. The product is injected in the superficial subcutaneous plane in retrograde injection (-Fig. 15).

This approach is used to correct the depression in the anterior border of the mandible caused by the premasseteric ligament and the volume of the muscle.

After the injection, the area can be shaped with moderate pressure, using the fingers.

\section{The Treatment of the Mandibular Angle and Ramus}

To treat this area, localize the mandibular angle through palpation. The horizontal rectangular area used to treat the mandibular line was already explained above.

Draw a rectangular area vertically, over the mandibular ramus, in the preauricular region and the inferior zygomatic lateral area, using two vertical lines of $3 \mathrm{~cm}$ approximately, with $2 \mathrm{~cm}$ of distance between them ( - Figs. $4,5,8,10$ ). The cannula entry point is in the mandibular angle. The product is placed in the subcutaneous plane in a retrograde injection. (-Figs. 16, 17, 18)

After the injection, using the second finger, press the product onto the mandibular bone to shape the area treated.

\section{Adverse Events}

Early complications related to the injection may occur, generally self-limited and mild, such as redness, edema and bruising in the areas of treatment. ${ }^{5,6}$
Other described adverse events are infection, nodules and foreign body granulomas, which are uncommon, but must be discussed with the patients before the treatment. ${ }^{19}$

The most severe complication is the vascular compromise. ${ }^{20-23}$ This is why the knowledge of anatomy is very important to apply the adequate technique., ${ }^{6,14}$

It is important to inject slowly, with low pressure, in the correct plane. ${ }^{20,23}$

It is paramount to perform the reflux maneuver aspiration for some seconds before the injection, especially when using a needle. If blood is seen in the syringe, the injection must be interrupted, and the needle withdrawn from the skin, to avoid undesired placement of the product into a vessel, which can lead to embolization and ischemia. The use of blunt cannulae is recommended in higher risk areas of vascular compromise. $^{23}$

Also, it is paramount to recognize signs of local ischemia such as blanching and pain. In this case, the injector must stop the injection and immediately start the following recommendations for treatment ${ }^{5,6,24}$ : ( - Fig. 19) apply warm compresses, infiltrate the area with injectable hyaluronidase, ${ }^{23,24}$ and consider administering aspirin, topical nitroglycerin and low-molecular weight heparin. ${ }^{5}$

Pay attention to stay in the subcutaneous plane, to avoid product placement into the parotid gland, which could lead to infection and parotiditis (-Figs. 2, 15-18). ${ }^{6}$

\section{Conclusion}

The shape of the jawline from the mandibular angle to the chin has a profound effect on an individual's appearance. ${ }^{6}$ The nonsurgical treatment with injectable fillers can effectively and safely reshape this area. The aesthetic goal of the rejuvenation approach is to redefine the mandibular angle, straightening the contour of the jaw.

Even in younger patients, beautification can be achieved through correction of constitutional deficit, as a small or recessed chin, for example; also, enhancement of the contour of the face can be attained, improving and defining the facial shape.

It is very important to understand the anatomy of beauty, which means the aspects that contribute to a 


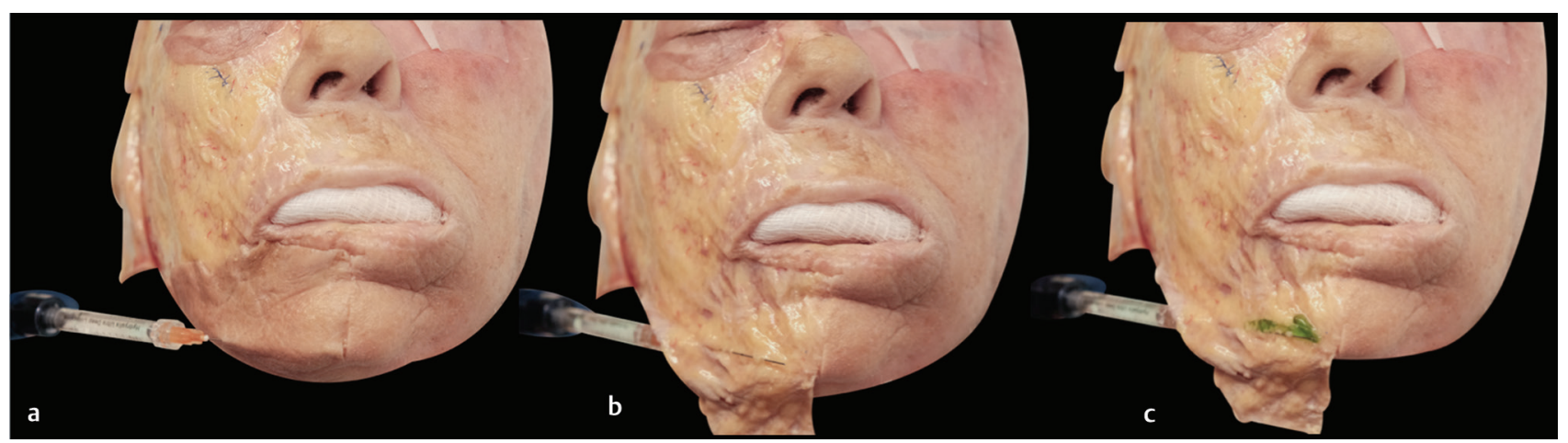

Fig. 12 Cadaveric dissection. (a) The superficial plane of injection in the chin. The cannula shape is seen below the skin. (b) The cannula in the superficial fat compartment. (c) The green colored gel place in the superficial fat.

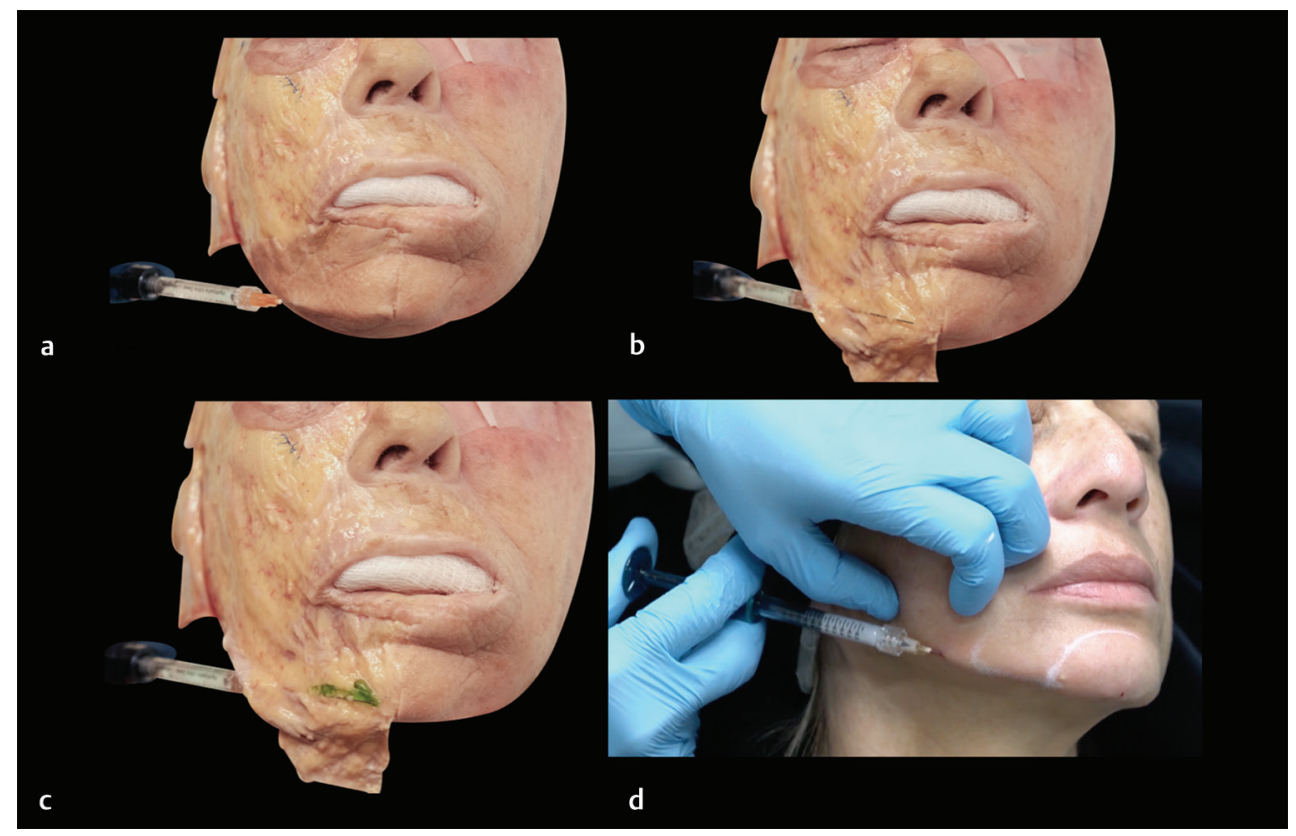

Fig. 13 Anatomical clinical correlation. (a) The superficial plane of injection in the chin. The cannula shape is seen below the skin. (b) The cannula in the superficial fat compartment. (c) The colored gel place in the superficial subcutaneous. (d) The injection of the prejowl region in the superficial subcutaneous plane

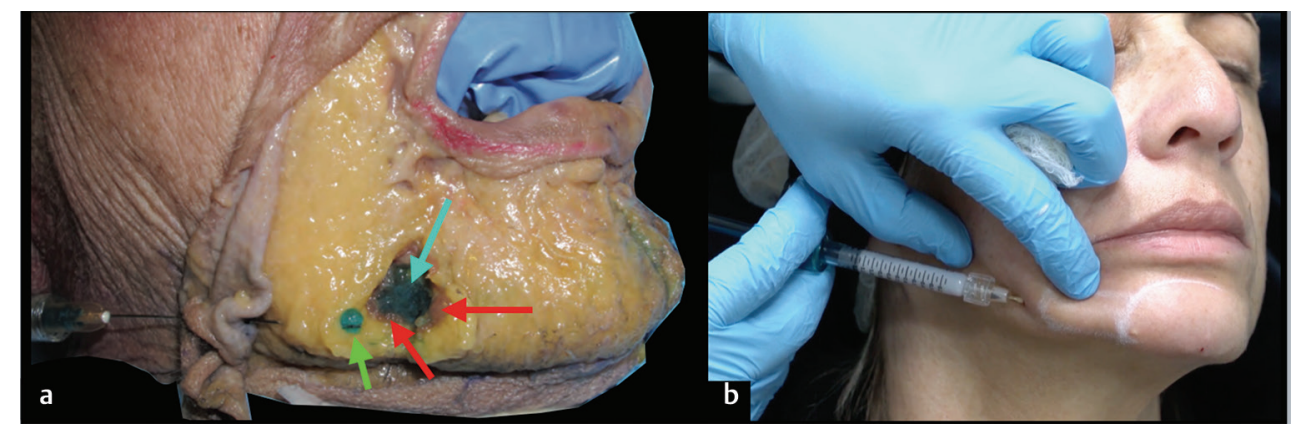

Fig. 14 Anatomical clinical correlation. (a) The colored gel placed in the superficial fat (green arrow). The gel placed in the deep fat compartment (light blue arrow). Between these planes, the depressor anguli oris (DAO) (red arrow). (b) The injection of the prejowl region in the deep fat. 




Fig. 15 (a) Cadaveric dissection showing the green colored gel placed in the superficial fat in the mandibular line, angle and ramus regions. The facial artery is shown in the deep fat, anterior to the masseter and ascending in the face. The superficial temporal artery. (b) The authors' approach to the mandibular line. The entry point in the prejowl area. In pink is marked the anterior border of the masseter, where the facial artery crosses the mandible. (c) The authors' approach to the mandibular line in another patient. The entry point in the prejowl area. In pink is marked the facial artery crossing the mandible. The second finger is palpating the mandibular angle, an important reference to the treatment.

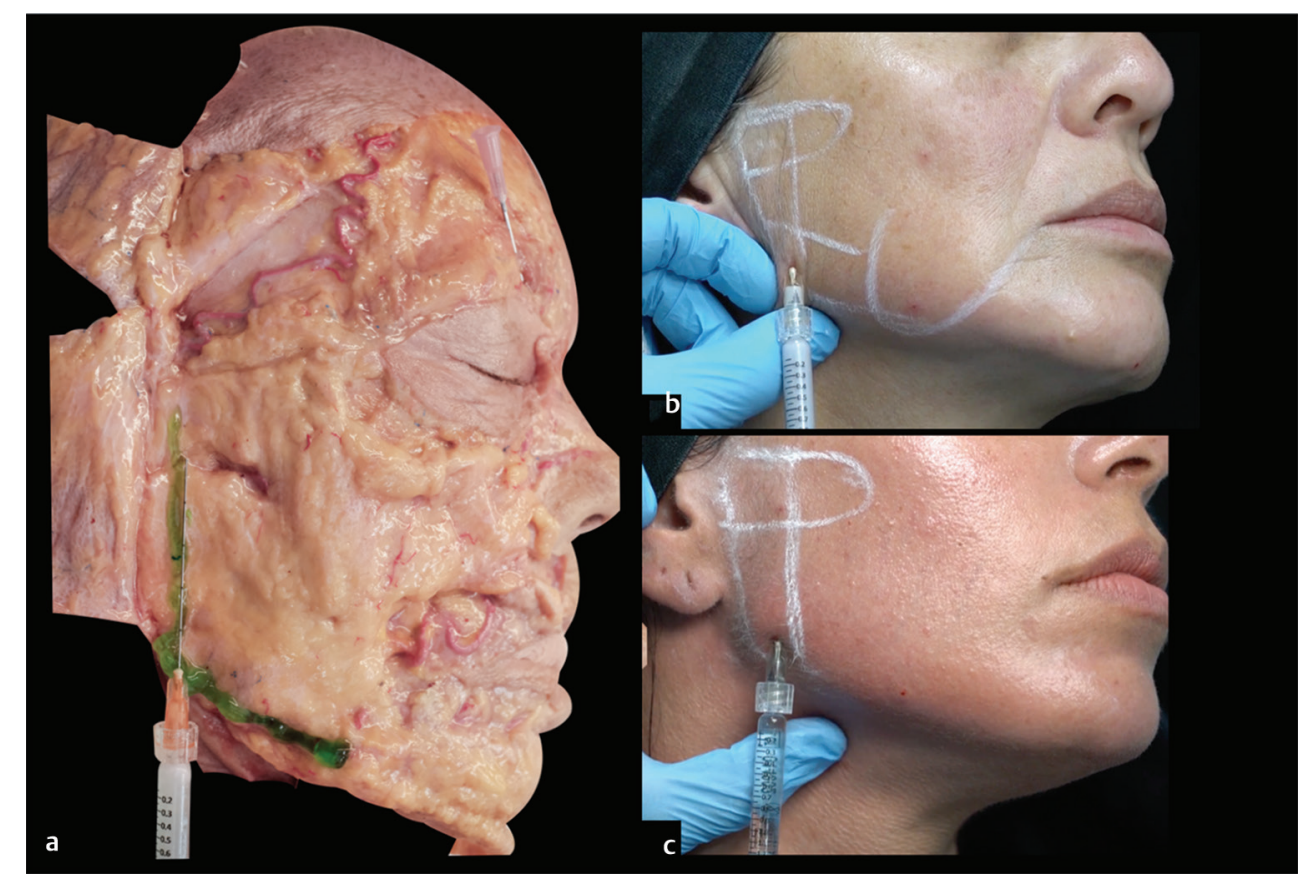

Fig. 16 (a) Cadaveric dissection showing the green colored gel placed in the superficial fat in the mandibular line, angle and ramus regions. The cannula shows the mandibular ramus, preauricular and inferior zygomatic lateral area treatments. (b and c) Approach to these regions in two different patients. 


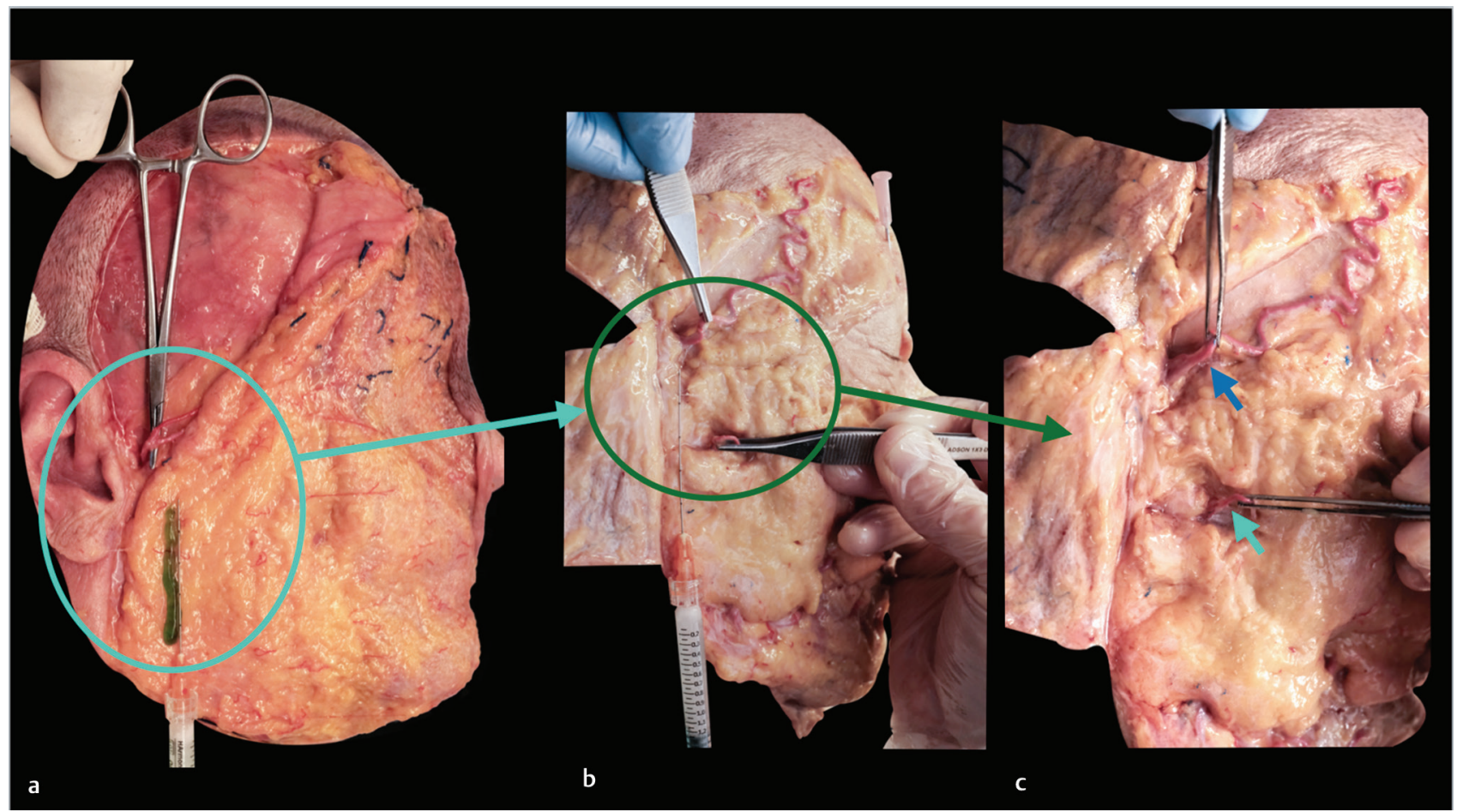

Fig. 17 (a) The superficial temporal artery is shown. The filler must be placed in the superficial fat (above the superficial musculoaponeurotic system [SMAS]) in the preauricular and inferior zygomatic regions. (b) The facial transverse artery, the superficial temporal artery, and the cannula in the superficial fat compartments above these structures. (c) Facial transverse artery (light blue arrow) is located below the superficial fat compartment and SMAS. The injection plane is above this structure. The superficial temporal artery (dark blue arrow).

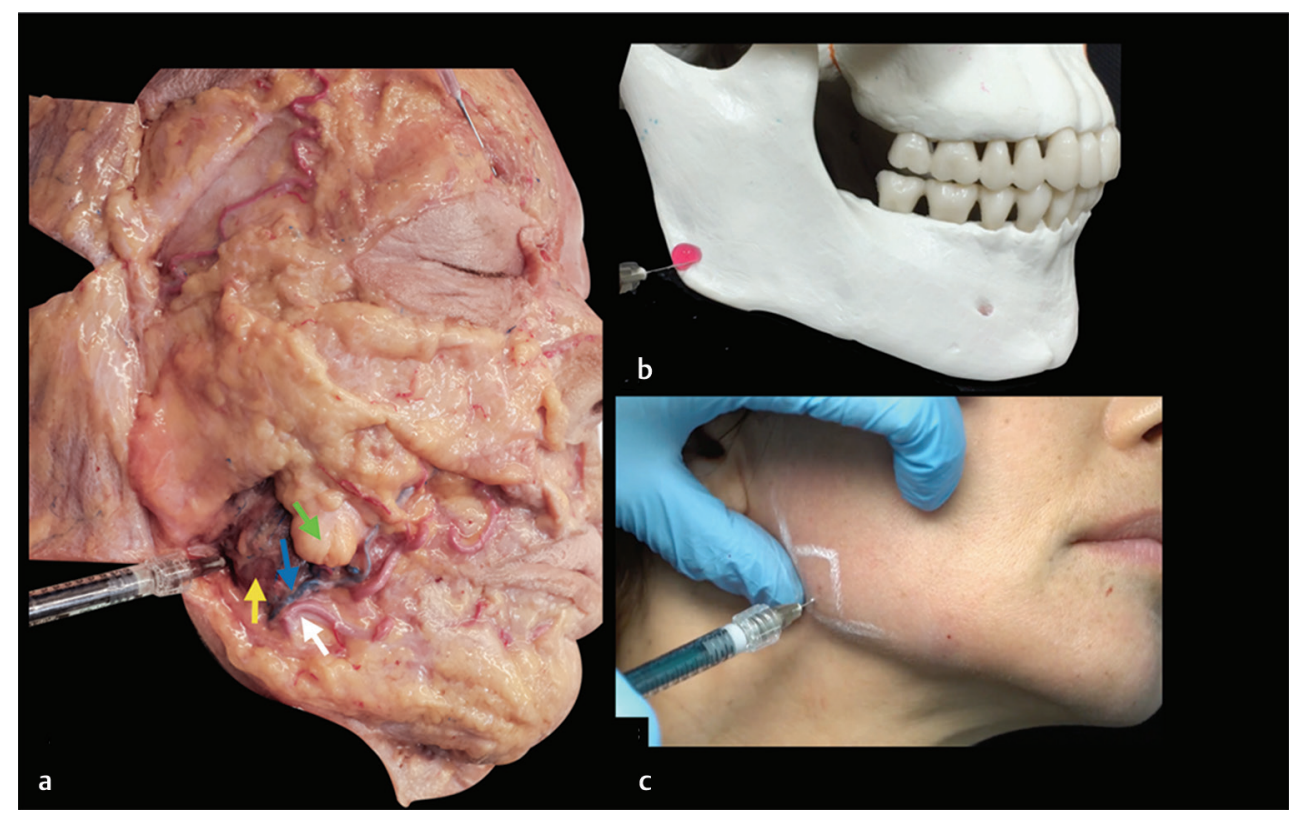

Fig. 18 (a) Simulating the treatment of the mandibular angle in the supraperiosteal plane. The masseter muscle (yellow), buccal fat pad (green), facial vein (blue) and facial artery (white arrow). (b) Red-colored gel in the mandibular angle. (c) Approach to the mandibular angle, injecting the filler in the supraperioteal plane, which is an option mainly when elongation of the mandibular line is desired.

beautiful face, as well as possess the knowledge of facial anatomy and the aging process. These will give resources to perform a good facial assessment and a proper aesthetic treatment plan, addressing the priorities of treatment for each patient, using the adequate technique.

\section{Conflicts of Interest}

Dr. Eduardo reports personal fees from Galderma and personal fees from Underskin outside the submitted work. Dr. Braz reports personal fees from Allergan, personal fees from merz, personal fees from U.SK Under Skin, 


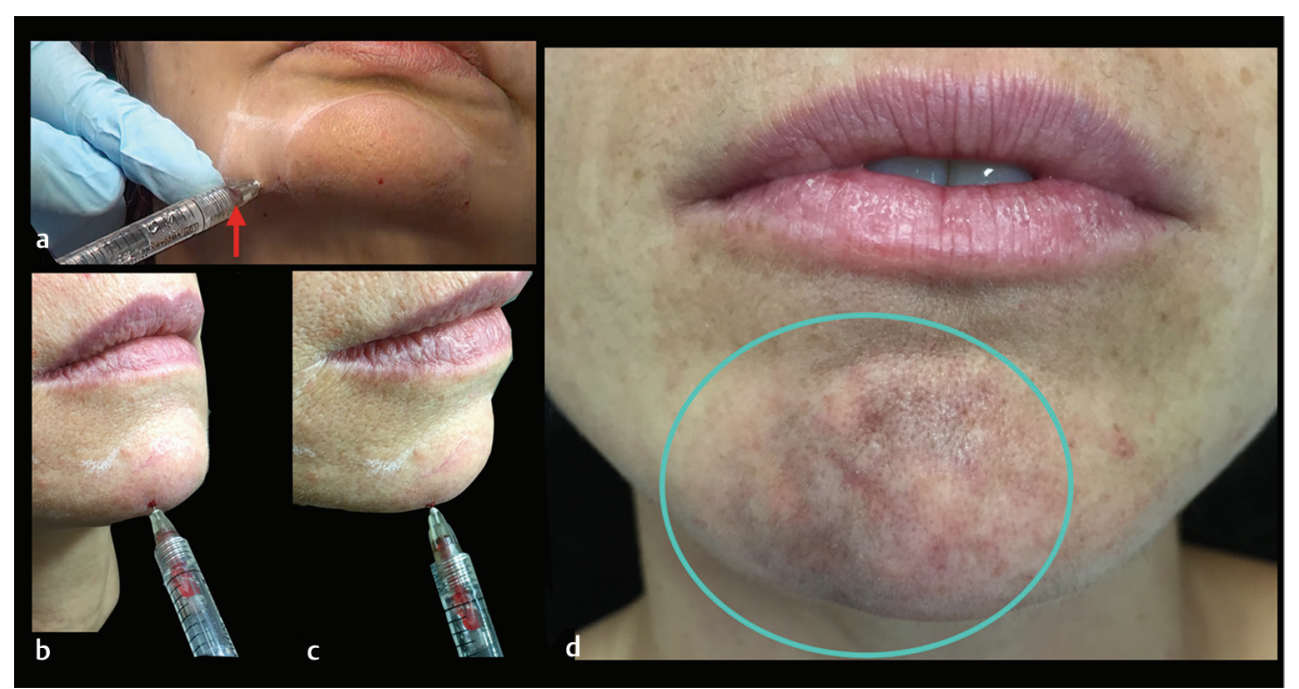

Fig. 19 (a) Filler injection into the prejowl area with needle. Reflux maneuver showing blood in the syringe. (b and c) Injection in the chin. Reflux maneuver is paramount. Blood can be seen in the syringe, alerting to discontinue the injection to avoid placement of the product into a vessel. (d) Livedo reticularis in the chin area, a sign of skin ischemia, probably secondary to the commitment of the submental artery, cervical branch of the facial artery. This patient received injection in the chin in a position similar to the pictures (b and $\mathbf{c}$ ) Of note, the possible positions of the submental artery, as shown in Figs. 6 and 7.

and personal fees from LÓreal outside the submitted work; in addition, Dr. Braz has a patent AB face technique pending.

\section{References}

1 Shamban, A. The signature feature: a new concept in beauty. J Cosmet Dermatol 2019 (e-pub ahead of print). doi: https:// doi.org/10.1111/jocd.12944

2 Sykes JM, Fitzgerald R. Choosing the best procedure to augment the chin: is anything better than an implant. ? Facial Plast Surg 2016;32(5):507-512

3 Sands NB, Adamson PA. Global facial beauty: approaching a unified aesthetic ideal. Facial Plast Surg 2014;30(2):93-100

4 Goodman GJ. The oval female facial shape- a study in beauty. Dermatol Surg 2015;41(12):1375-1383

5 Vazirnia A, Braz A, Fabi SG. Nonsurgical jawline rejuvenation using injectable fillers. J Cosmet Dermatol 2019;00:1-8

6 Moradi A, Shirazi A, David R. Non surgical chin and jawline augmentation using calcium hydroxylapatite and hyaluronic acid fillers. Facial Plast Surg 2019;35(2):140-148

7 Vanaman Wilson MJ, Jones IT, Butterwick K, Fabi SG. Role of nonsurgical chin augmentation in full face rejuvenation: a review and our experience. Dermatol Surg 2018;44(7):985-993

8 de Maio M. Ethnic and gender considerations in the use of facial injectables: male patients. Plast Reconstr Surg 2015;136(5, Suppl):40S-43S

9 Avelar LET, Cazerta CEP, Avè MN, Shitara DI. Dynamic changes of facial supporting cornerstones (pillars): considerations in aesthetic approach. J Drugs Dermatol 2018;17(4):466-470

10 Toledo Avelar LE, Cardoso MA, Santos Bordoni L, de Miranda Avelar L, de Miranda Avelar JV. Aging and sexual differences of the human skull. Plast Reconstr Surg Glob Open 2017;5(4):e1297

11 Wong $\mathrm{CH}$, Mendelson B. Newer understanding of specific anatomic targets in the aging face as applied to injectables: aging changes in the craniofacial skeleton and facial ligaments. Plast Reconstr Surg 2015;136(5, Suppl):44S-48S

12 Reece EM, Pessa JE, Rohrich RJ. The mandibular septum: anatomical observations of the jowls in aging-implications for facial rejuvenation. Plast Reconstr Surg 2008;121(4):1414-1420
13 de Maio M, Wu WTL, Goodman GJ, Monheit G; Alliance for the Future of Aesthetics Consensus Committee. Facial assessment and injection guide for botulinum toxin and injectable hyaluronic acid fillers: focus on the lower face. Plast Reconstr Surg 2017; 140(3):393e-404e

14 Juhász MLW, Marmur ES. Examining the efficacy of calcium hydroxylapatite filler with integral lidocaine in correcting volume loss of the jawline- a pilot study. Dermatol Surg 2018;44(8):1084-1093

15 Braz A, Sakuma T. Preenchimento do mento e contorno de mandíbula. In: Atlas de anatomia e preenchimento global da face. Ed. GUanabara Koogan, Rio de Janeiro, 1a edição 2019

16 Braz A, Humphrey S, Weinkle S, et al. Lower face: clinical anatomy and regional approaches with injectable fillers. Plast Reconstr Surg 2015;136(5, Suppl):235S-257S

17 Suwanchinda A, Rudolph C, Hladik C, et al. The layered anatomy of the jawline. J Cosmet Dermatol 2018;17(4):625-631

18 Batra AP, Mahajan A, Gupta K. Marginal mandibular branch of the facial nerve: An anatomical study. Indian J Plast Surg 2010;43(1):60-64

19 Kadouch JA. Calcium hydroxylapatite: a review on safety and complications. J Cosmet Dermatol 2017;16(2):152-161

20 Chatrath V, Banerjee PS, Goodman GJ, Rahman E. Softtissue filler-associated blindness: a systematic review of case reports and case series. Plast Reconstr Surg Glob Open 2019;7(4):e2173

21 Yuan JT, Chang TW, Yu SS, Arron ST. Mental artery occlusion from poly L-lactic acid injection at the lateral chin. Dermatol Surg 2017;43(11):1402-1405

22 Robinson DM. In vitro analysis of the degradation of calcium hydroxylapatite dermal filler: a proof-of-concept study. Dermatol Surg 2018;44(Suppl 1) :S5-S9

23 Heydenrych I, Kapoor KM, De Boulle K, et al. A 10-point plan for avoiding hyaluronic acid dermal filler-related complications during facial aesthetic procedures and algorithms for management. Clin Cosmet Investig Dermatol 2018;11:603-611

24 Fang M, Rahman E, Kapoor KM. Managing complications of submental artery involvement after hyaluronic acid filler injection in chin region. Plast Reconstr Surg Glob Open 2018;6(5):e1789 